\title{
The effects of flash release conditions on the phenolic compounds and antioxidant activity of Pinot noir red wine
}

\author{
Justyna Samoticha $^{1} \cdot$ Aneta Wojdyło $^{1} \cdot$ Joanna Chmielewska $^{2} \cdot$ Jan Oszmiański $^{1}$
}

Received: 26 July 2016 / Revised: 22 September 2016 / Accepted: 28 October 2016 / Published online: 9 November 2016

(C) The Author(s) 2016. This article is published with open access at Springerlink.com

\begin{abstract}
This study investigated the effects of a flash release versus traditional maceration expansion on the content of phenolic compounds (by LC-MS, UPLC-PDA), antioxidant activity (ABTS and FRAP), and other physical and chemical properties of wine from Pinot noir cultivar. The content of polyphenols in a must obtained by the flash release technology was higher than when using a traditional method. Flash release expansion improved the extraction of polyphenol compounds, especially anthocyanins, as well as color properties and antioxidant activity. However, during maturation and storage, the content of polyphenols significantly decreased, especially in the wine exposed to the flash release expansion. Despite lower total polyphenols content (1435 vs. $1686 \mathrm{mg} / \mathrm{L}$ in control), the final flash release wine contained more anthocyanins which resulted in approximately 2 times higher antioxidant activity. High correlation between antioxidant activity $\left(r^{2}=0.84\right.$ and 0.79 for ABTS and FRAP assay, respectively) and the content of anthocyanins was determined in both types of examined wines. Changes in color were also observed in the must prepared by flash release versus traditional maceration. During fermentation, $L^{*}$ and $a^{*}$ parameters, the variables associated with more light and red color, increased,
\end{abstract}

Aneta Wojdyło

aneta.wojdylo@up.wroc.pl

1 Department of Fruit, Vegetable and Cereals Technology, The Faculty of Food Science, Wrocław University of Environmental and Life Sciences, 37 Chełmońskiego Street, 51-630 Wrocław, Poland

2 Department of Food Storage and Technology, The Faculty of Food Science, Wrocław University of Environmental and Life Sciences, 37 Chełmońskiego Street, 51-630 Wrocław, Poland and during maturation, a rise in $b^{*}$ parameter, associated with yellow color, was observed.

Keywords Wine - Maceration · Quality · Polyphenols · Chemical property $\cdot$ Storage

\section{Introduction}

Horticultural plants are very important for human diet as sources of vitamins, minerals and dietary fiber, and they become a significant part of human life moreover due to their medicinal and environmental uses as well as esthetics and economic values [1-4]. Grape (Vitis vinifera L.) is one of the major crops cultivated around the world. Its production in Europe is significant, and in 2013, it exceeded 29 million tons. Therefore, over $60 \%$ of global wine production is attributable to Europe. Main European producers of wine include France, Italy and Spain [5]; however, wine production in Poland grows year by year [6].

Popular red table wines are Cabernet sauvignon, Merlot, or Syrah [7]. As compared to them, Pinot noir wines tend to be lighter in color due to lower concentration of anthocyanins and tannins in grapes. Pinot noir grapes come originally from Burgundy, France. Table wines from this cultivar are considered fine wines and achieve the highest prices per bottle anywhere in the world [8]. The quality of red wine is highly associated with the degree of grape maturity at harvest and wine production technology (processes and conditions). Wine is a complex matrix of volatile and nonvolatile compounds [9]. Phenolic components of red grape cultivars (anthocyanins, flavonols, catechins and other flavonoids) are important for high-quality red wine and contribute to its organoleptic properties (e.g., color and astringency). They 
also contribute to multiple biological effects, such as antioxidant activity of grapes and wine [7, 10, 11].

Red wine production involves grape harvesting, juice processing and alcoholic fermentation. All these steps may affect the level of antioxidants in the grape must and wine. Recent interest in health-promoting foods has boosted the search for technological solutions that may affect or increase antioxidant content in wine [10]. For grape cultivars with lower polyphenolic potential, such as Pinot noir, a long period of maceration during alcoholic fermentation would be recommended to improve color properties and phenolics content [7]. During red wine production, the grapes are mostly crushed and destemmed prior to fermentation. In contrast to white wine production, the must is fermented together with the skins and seeds and, in fact, wine-making techniques have been optimized to maximize extraction of phenolic compounds, especially anthocyanins from the skins [10]. Several technologies have been tried to improve grape must yield and phytochemical content, i.e., enzymatic treatment, irradiation, pulsed electric field, or microwave maceration. They improve juice yield, but may also require time and significant costs. To speed the processing time and improve the yield and nutritional quality of wine, the flash release technology can be used $[12,13]$.

The flash release (FR) process consists of rapidly heating the grapes and then applying strong vacuum. This method has been proposed to extract more phytochemicals from grapes. Flash release system has been used since the 1990s and is installed at wineries in Europe, South Africa and America, Australia, China and USA. Additionally, it can be also used for other fruit than grapes, especially red colored, to extract more anthocyanins [14]. At high vacuum, the boiling point of water in the tissues is much lower than the temperature of the plant material $\left(60-90{ }^{\circ} \mathrm{C}\right)$. The plant material expands or disintegrates due to instantaneous evaporation of water, and micro-channels are formed in the tissues. Lower pressure (in a flash chamber) and higher initial fruit temperature promote extraction of polyphenolics into the juice as a result of a very dynamic cell rupture caused by flash vacuum expansion in the grape skins. The technology also showed improved juice yield and anthocyanin extraction as compared to enzymatic treatment $[12$, 14].

Wine production in Poland is growing and becoming more popular. However, no literature concerning this region is available. Even though Poland produces more white wine, an indication of appropriate technology could be useful for winemakers who want to develop their production of red wine.

The aim of this study was to investigate the effects of flash release on phenolic profiles and content (qualitatively by LC-MS and quantitatively by UPLC-PDA), and antioxidant activity (ABTS and FRAP) of the wine produced from Pinot noir cv. Measurements were taken in two variants of the wine (produced with traditional or with flash release). Analysis of $\mathrm{pH}$, total acidity, sugar content, polyphenol content, antioxidant activity and color were conducted at every step of the production in (1) fresh must, (2) wine after fermentation and (3) after 6 months of maturation. Etanol was only measured in wine. This research provides an overall profile of the wine from Pinot noir grapes in term of its chemical composition and potential healthpromoting properties. Additionally, the effects of flash release maceration on polyphenol content were shown.

\section{Materials and methods}

\section{Chemicals}

2,2'-Azinobis(3-ethylbenzothiazoline-6-sulfonic acid) (ABTS), 6-hydroxy-2,5,7,8-tetramethylchroman-2-carboxylic acid (Trolox), 2,4,6-tri(2-pyridyl)striazine (TPTZ) and methanol were purchased from Sigma-Aldrich (Steinheim, Germany). (-)-Epicatechin, (+)-catechin, procyanidin $\mathrm{B} 1, p$-coumaric acid, and quercetin derivatives were purchased from Extrasynthese (Lyon, France). Acetonitrile for ultra-performance liquid chromatography (UPLC; Gradien grade) and ascorbic acid were from Merck (Darmstadt, Germany). UPLC grade water, prepared by HLP SMART 1000s system (Hydrolab, Gdańsk, Poland), was additionally filtrated through a $0.22-\mu \mathrm{m}$ membrane filter immediately before use.

\section{Plant material}

The study involved the grapes of Pinot noir cv. The material was collected from a vineyard Jaworek in Miękinia (N51 ${ }^{\circ} 10^{\prime} 30.110^{\prime \prime}$, E16 $\left.45^{\prime} 6.875^{\prime \prime}\right)$, near Wrocław (Poland), in September 2014. The harvested berries were fully mature.

\section{Wine production}

Two variants of wine were produced. In both, the fruits were first destemmed and crushed (Thermomix, Vorwerk). One portion (ca. $2 \mathrm{~kg}$ ) of grapes was exposed to flash release maceration (FR). These fruits were heated to $90{ }^{\circ} \mathrm{C}$ and closed hermetically in a vacuum tank. After opening a valve, vacuum was rapidly applied $(0.1 \mathrm{~atm})$ for $10 \mathrm{~min}$. The result of a rapid evaporation was bursting the fruit tissues and temperature decrease to $35^{\circ} \mathrm{C}$. The second batch of fruits (ca. $2 \mathrm{~kg}$ ) was not exposed to vacuum, but they 
were only pressed in a laboratory press. The resulting must was supplemented with nutrients in the form of SIHA Proferm Plus at $0.4 \mathrm{~g} / \mathrm{L}$ (Eaton, Begerow, Langenlonsheim, Germany), sulfates as $\mathrm{K}_{2} \mathrm{~S}_{2} \mathrm{O}_{5}$ (POCh Gliwice, Poland) at $0.05 \mathrm{~g} / \mathrm{L}$ and yeast $S$. cerevisiae Lalvin RC 212 at $0.2 \mathrm{~g} / \mathrm{L}$. Fermentation was conducted at $20{ }^{\circ} \mathrm{C}$ for 16 days. After that, the wine was maturated at $4{ }^{\circ} \mathrm{C}$ for 6 months.

\section{Physicochemical analyses}

Titratable acidity (TA) and $\mathrm{pH}$ were determined by titration aliquots (Schott Titroline $7500 \mathrm{KF}$ Volumetric KF Titrator; Mainz, Germany) of $10 \mathrm{~mL}$ of must or wine, by $0.1 \mathrm{~N} \mathrm{NaOH}$ to an end point of $\mathrm{pH} 7.0$ using an automatic $\mathrm{pH}$ titration system and expressed as $\mathrm{g}$ of tartaric acid in $100 \mathrm{~mL}$. Alcohol content in wine was determined by using oscillating densimeter DMA 4500M (Anton Paar, Graz, Austria), with result as the volume percent (\%).

\section{Determination of sugar content by the HPLC method}

Sugar content was measured using a Thermo Separation Products HPLC with refractive index (RI) detector. Separation of sugars was carried out using a Rezex RCM-monosaccharide column $(300 \mathrm{~mm} \times 7.8 \mathrm{~mm}$; Phenomenex, Torrance, CA) with the column temperature maintained at $65{ }^{\circ} \mathrm{C}$ and flow rate of $0.6 \mathrm{~mL} / \mathrm{min}$. The samples were eluted according to the isocratic method, for the mobile phase, twice distilled water was used and also a refractive index detector for identification. Results are expressed in grams per $100 \mathrm{~mL}$.

\section{Identification of polyphenols by the LC-PDA-MS method}

The extraction of grape fruits for their polyphenols analysis was performed as described previously by Wojdyło et al. [15]. Must and wine samples were filtrated through a $0.22-\mu \mathrm{m}$ membrane filter before analysis. The samples were analyzed by using an Acquity UPLC system (Waters, Milford, MA) with a Q-Tof mass spectrometer (Waters, Manchester, U.K.). An Acquity UPLC BEH C18 column $(2.1 \times 100 \mathrm{~mm}, 1.7 \mu \mathrm{m}$; Waters Corporation, Milford, USA) was used to perform the chromatographic separation of $5 \mu \mathrm{L}$ of each sample injected into a gradient system at a flow rate of $0.42 \mathrm{~mL} / \mathrm{min}$. The column and sample managers were maintained at 30 and $10{ }^{\circ} \mathrm{C}$, respectively. The mobile phase consisted of $4.5 \%$ formic acid in deionized water (A) and acetonitrile (B). Samples were eluted according to a linear gradient: $0-12 \mathrm{~min}$, $1-25 \% \mathrm{~B} ; 12-12.5 \mathrm{~min}, 100 \% \mathrm{~B} ; 12.5-13.5 \mathrm{~min}, 1 \% \mathrm{~B}$. The conditions of MS analysis were as follows: cone voltage of $35 \mathrm{~V}$, capillary voltage of $2000 \mathrm{~V}$, spectra rate, 3.0
$\mathrm{Hz}$, source and desolvation temperature were of 100 and $250{ }^{\circ} \mathrm{C}$, respectively, desolvation gas flow as nitrogen with rate of $300 \mathrm{~L} / \mathrm{h}$. To ensure that mass was measured accurately, leucine-enkephalin was used as the reference lock-mass compound at a concentration of $500 \mathrm{pg} /$ $\mu \mathrm{L}$. Analysis was made by ionization mode at negative $[\mathrm{M}-\mathrm{H}]^{-}$and positive $[\mathrm{M}+\mathrm{H}]^{+}$before and after fragmentation within mass scanning from $\mathrm{m} / \mathrm{z}, 100$ to 1700 . The data were collected by Mass-Lynx TM v 4.1 software. Quantification was achieved by injection of solutions of known concentrations ranging from 0.05 to $5 \mathrm{mg} /$ $\mathrm{mL}\left(R^{2} \leq 0.9998\right)$ of phenolic compounds as standards. The results were expressed as $\mathrm{mg}$ per $100 \mathrm{~mL}$ for must and wine.

\section{Analysis of antioxidant activity}

The free radical scavenging capacities were determined using the ABTS method described by $\mathrm{Re}$ et al. [16] and FRAP (ferric reducing antioxidant power) method described by Benzie and Strain [17]. Determination methods were performed using a UV-2401 PC spectrophotometer (Shimadzu, Kyoto, Japan). All antioxidant activity analyses were done in triplicate, and results were expressed as millimoles of Trolox per $1 \mathrm{~mL}$.

\section{Color measurement}

The color of must and wine was determined using an A5 Chroma-Meter (Minolta CR300, Osaka, Japan), refereeing to color space CIE $L^{*} a^{*} b^{*}$. Samples were measured against a white ceramic reference plate $\left(L^{*}=93.80 ; a^{*}=31.58\right.$; $\left.b^{*}=33.23\right)$. All measurements were done in triplicate. The total change in color of wine after fermentation and after storage was expressed as $\Delta E$.

$\Delta E=\sqrt{\left(L_{0}^{*}-L^{*}\right)^{2}+\left(a_{0}^{*}-a^{*}\right)^{2}+\left(b_{0}^{*}-b^{*}\right)^{2}}$

$L_{0}^{*}, a_{0}^{*}$ and $b_{0}^{*}$ were the value of grape must color, and $L^{*}$, $a^{*}, b^{*}$ were value of wine after fermentation and after maturation.

$L^{*}$ is a measure of lightness, from completely opaque (0) to completely transparent (100), while $a^{*}$ is a measure of redness (or $-a^{*}$ of greenness) and $b^{*}$ of yellowness (or $-b^{*}$ of blueness) [18].

\section{Statistical analysis}

Statistical analysis was conducted using Statistica version 10 (StatSoft, Krakow, Poland). Significant differences $(p \leq 0.05)$ between means were evaluated by one-way ANOVA and Duncan's multiple-range test. All analyses were done in triplicate. 


\section{Results and discussion}

\section{Chemical composition}

Chemical composition of the investigated must and wine of Pinot noir cv. obtained by means of flash release (FR) is shown in Table 1. Alcohol content was measured only in wine, while $\mathrm{pH}$, total acidity and sugar content were estimated in both must and wine. Total sugar content $(\mathrm{g} / 100 \mathrm{~mL})$ was higher in the control must $(18.45 \mathrm{~g} / 100 \mathrm{~mL})$ than in the FR must $(17.72 \mathrm{~g} / 100 \mathrm{~mL})$. The must contained rhamnose, saccharose, fructose and glucose. Sugar content in the wine after fermentation and maturation was very low, with rhamnose being the only detected sugar component. After maturation, rhamnose ranged from 0.85 to $0.90 \mathrm{~g} / 100 \mathrm{~mL}$, and its content did not change significantly during storage. Very low glucose content also remained at the same level, thus indicating the fermentation process was over. Sugar content in the grapes determines alcohol content in the wine [7]. The main solutes apart from sugars are organic acids, such as tartaric, malic, or citric acid. Tartaric and malic acids account for over $90 \%$ of all organic acids present in grapes [10]. In our study, $\mathrm{pH}$ and total acidity changed during wine production. The highest $\mathrm{pH}$ was measured in the wine after fermentation (3.536 and 3.371) and the lowest in the wine after aging (3.282 and 3.328 for control and FR wine, respectively). These results are consistent with the literature cited above. However, the investigated wines were characterized by around two times higher total acidity ( $\mathrm{g}$ of tartaric acid/L) than Pinot noir wines produced in other countries. The must contained 10.45 and $12.55 \mathrm{~g}$ of tartaric acid/L, and the variant obtained by FR was more abundant in organic acids. This might be related to a more efficient release of organic acids from the fruit tissue. FR must was significantly more acidic than the control batch. Must acidity decreased along the fermentation and maturation processes. Total acidity was measured at $7.97 \mathrm{~g}$ of tartaric $\mathrm{acid} / \mathrm{L}$ for control and $9.26 \mathrm{~g}$ of tartaric acid/L for FR wine. Therefore, to reduce wine acidity, malolactic fermentation could be used. This process results in a lowered acidity and may also affect other wine quality parameters. Organic acids help to stabilize color and mouthfeel that improve wine quality. At low $\mathrm{pH}$, wine is less liable to microbial spoilage [7]. Pinot noir grapes are characterized by $\mathrm{pH}$ $3.08-3.17$ and acidity $7.40-11.20 \mathrm{~g}$ of tartaric acid/L [19]. The values for wine do not differ significantly from the results for grapes. Song et al. [19] reported no significant changes in $\mathrm{pH}(3.30-3.50)$ or total acidity (2.58-2.76 g of tartaric acid/L) in Pinot noir wine from the grapes grown in shade or exposed to UV, respectively. Urcan et al. [20] found out that $\mathrm{pH}$ of Pinot noir wine from Romania ranged from 3.26 to 3.32 and total acidity from 5.85 to $7.40 \mathrm{~g}$ of

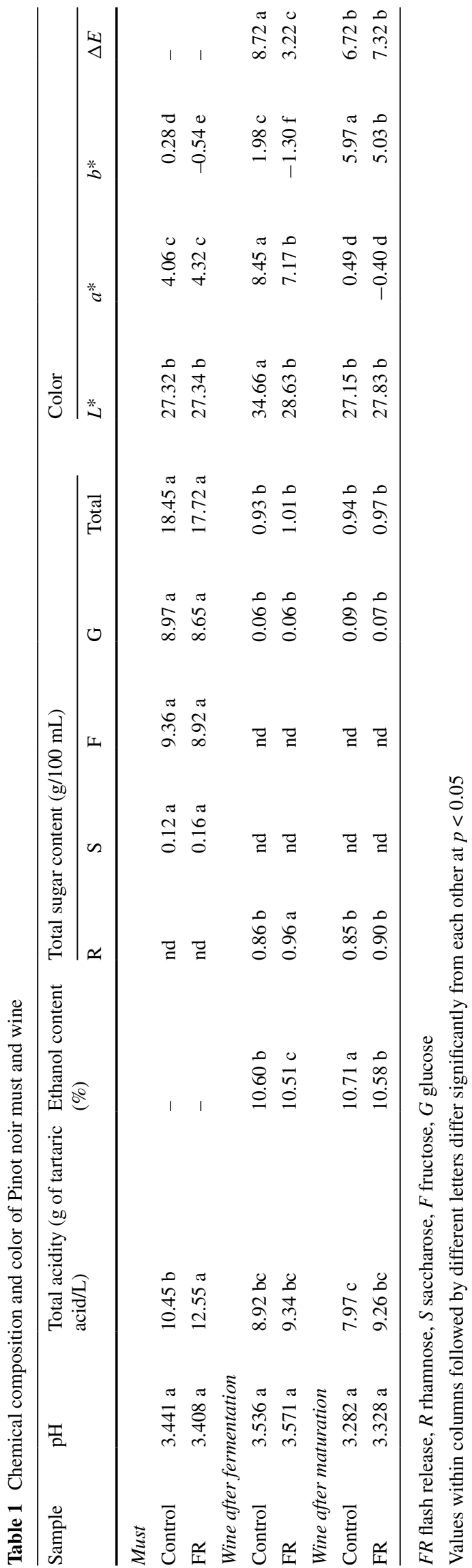


tartaric acid/L, while Costa et al. [7] reported the acidity of Pinot noir to be 3.25-3.45 (from Portuguese grapes) and 5.4-5.6 $\mathrm{g}$ tartaric acid/L (from French grapes) in wine, with average $\mathrm{pH}$ value $3.15-3.25$.

\section{Polyphenols}

Polyphenols are another major group of nutrients in grapes apart from sugars and organic acids. Their primary role is to contribute to the flavor and color of wine. Phenolics are also the main antioxidants present in grapes and wine. Many factors (cultivars, sunlight or UV radiation) determine polyphenol content in grapes and wine. Location in grape berry tissue and their chemical interactions (with each other and with other grape compounds) and winemaking process are known to limit their content in wine. Besides, these technological factors may affect wine quality by means of profitable maceration, fermentation and storage conditions.

Four groups of phenolic compounds were identified by LC-MS QTof in Pinot noir must and wine (Table 2). Two phenolic acids, eight flavan-3-ols, four flavonols and five anthocyanins were detected. Quantitative content of polyphenolic compounds is presented in Table 3. Maceration treatment, fermentation and maturation processes affected the content of each group of phenolics. In general, red wines are richer in polyphenols (1000$3500 \mathrm{mg} / \mathrm{L}$ gallic acid equivalents) than white wines $(100-250 \mathrm{mg} / \mathrm{L}$ gallic acid equivalents) [10], which is a result of production process involving extensive skin and seed contact.

Pinot noir wine from this study, obtained by FR maceration, had higher content of phenolics in the must and wine after fermentation. FR resulted in greater reduction in the impedance of the grape skin and caused more extensive cell damage than heat or enzyme treatment. It was consistent with higher polyphenol extraction obtained by flash vacuum expansion than traditional method of maceration. The flash vacuum treatment at $90^{\circ} \mathrm{C}$ and $1 \mathrm{kPa}$ yielded the highest total pool of polyphenols [12]. The FR must contained $1878 \mathrm{mg} / \mathrm{L}$ of total polyphenols, i.e., by $24.8 \%$ more than the control must $(1505 \mathrm{mg} / \mathrm{L})$. During the fermentation process, when the transformation of polyphenolic compounds occurred, differences between the studied variants diminished. The young wine obtained by FR contained by $19.6 \%$ more polyphenols than the wine produced by traditional maceration. Alcoholic fermentation of red wine generally involves partial crushing of grapes followed by yeast-mediated transformation of grape sugars and other compounds into ethanol and other secondary metabolites [21]. The content of phenolics at the final stage (after maturation) amounted to $1687 \mathrm{mg} / \mathrm{L}$ for traditional maceration and $1435 \mathrm{mg} / \mathrm{L}$ for FR method; however, no statistically significant differences were found $(p<0.05)$.
Table 2 Groups of phenolic compounds identified by the LC-PDAMS of Pinot noir must and wine

\begin{tabular}{|c|c|c|c|c|}
\hline \multirow[t]{2}{*}{ Compound } & \multirow{2}{*}{$t_{R}(\min )$} & \multirow{2}{*}{$\lambda_{\max }(\mathrm{nm})$} & \multicolumn{2}{|c|}{$[\mathrm{M}-\mathrm{H}]^{-}(m / z)$} \\
\hline & & & MS & MS/MS \\
\hline \multicolumn{5}{|l|}{ Anthocyanins } \\
\hline $\begin{array}{l}\text { Delphinidin-3-O-glu- } \\
\text { coside }\end{array}$ & 3.49 & $521 / 278$ & 465.1034 & 303.0496 \\
\hline Cyanidin-3-O-glucoside & 4.05 & $516 / 277$ & 449.1107 & 287.0571 \\
\hline Petunidin-3-O-glucoside & 4.38 & $521 / 279$ & 479.1211 & 317.0635 \\
\hline Peonidin-3-O-glucoside & 4.92 & $515 / 279$ & 463.1247 & 301.073 \\
\hline Malvidin-3-O-glucoside & 5.16 & $526 / 277$ & 493.1379 & 331.0851 \\
\hline \multicolumn{5}{|l|}{ Flavan-3-ols } \\
\hline Procyanidin trimer & 2.52 & 278 & 865.1967 & 289.0723 \\
\hline Procyanidin dimer & 2.79 & 278 & 577.1398 & 289.0758 \\
\hline Procyanidin dimer & 2.93 & 277 & 577.1525 & 289.0723 \\
\hline Procyanidin dimer & 3.49 & 278 & 577.1299 & 289.0723 \\
\hline Procyanidin dimer & 4.06 & 277 & 577.1525 & 289.0723 \\
\hline Procyanidin dimer & 4.44 & 277 & 577.1398 & 289.0723 \\
\hline$(+)$-Catechin & 4.44 & 276 & 289.0723 & \\
\hline (-)-Epicatechin & 5.54 & 277 & 289.0653 & \\
\hline \multicolumn{5}{|l|}{ Phenolic acids } \\
\hline Caftaric acid & 2.46 & $327 / 243$ & 311.0425 & 179.0349 \\
\hline Coutaric acid & 3.29 & $312 / 242$ & 295.0429 & 163.0406 \\
\hline \multicolumn{5}{|l|}{ Flavonols } \\
\hline Quercetin-3-O-glucoside & 5.83 & $352 / 242$ & 463.0843 & 301.0354 \\
\hline $\begin{array}{l}\text { Quercetin-3-O-glucu- } \\
\text { ronide }\end{array}$ & 5.93 & $352 / 243$ & 477.0709 & 301.0354 \\
\hline Quercetin-3-O-glucoside & 6.00 & $351 / 244$ & 463.0887 & 301.0354 \\
\hline $\begin{array}{l}\text { Isorhamnetin-3-O- } \\
\text { glucoside }\end{array}$ & 7.10 & $352 / 270$ & 477.0977 & 315.0549 \\
\hline
\end{tabular}

Changes at this stage should be more closely investigated, and appropriate measures should be taken to counteract them in the future. As far as polyphenol content was concerned, the traditional method of wine production seemed more advantageous.

Morel-Salmi et al. [14] reported that FR process in different grape cultivars (Grenache, Mourvedre, Carignan) allowed for a fast extraction of all phenolic compounds (hydroxycinnamic acids, flavonols, anthocyanins, catechins, proanthocyanidins) and may be used to produce polyphenol-enriched grape juices. Increasing the duration of high-temperature exposure during FR further improved the extraction of phenolic compounds, but also accelerated their conversion to derivatives. Furthermore, the authors claimed that the concentration of all classes of phenolic compounds decreased throughout the fermentation in the liquid phase (they rapidly proceed to various degradation and reaction products), while in the musts fermented on pomace, this was compensated by further extraction. 
Table 3 Polyphenols content (in $\mathrm{mg} / \mathrm{L}$ ) estimated by UPLCPDA-FL and antioxidant activity (by ABTS and FRAP assay, as $\mu \mathrm{mol}$ Trolox $/ \mathrm{mL}$ ) of Pinot noir must and wine

\begin{tabular}{|c|c|c|c|c|c|c|c|}
\hline \multirow[t]{2}{*}{ Sample } & \multirow[t]{2}{*}{ Sum of polyphenols } & \multirow[t]{2}{*}{ Anthocyanins } & \multirow[t]{2}{*}{ Flavan-3-ols } & \multirow[t]{2}{*}{ Phenolic acids } & \multirow[t]{2}{*}{ Flavonols } & \multicolumn{2}{|c|}{$\begin{array}{l}\text { Antioxidant } \\
\text { activity }\end{array}$} \\
\hline & & & & & & ABTS & FRAP \\
\hline \multicolumn{8}{|l|}{ Must } \\
\hline Control & $1505 \mathrm{~b}$ & $25.8 \mathrm{c}$ & $1406 \mathrm{a}$ & $57.0 \mathrm{~d}$ & $15.9 \mathrm{a}$ & $56.5 \mathrm{c}$ & $37.9 \mathrm{c}$ \\
\hline FR & $1878 \mathrm{a}$ & 203 a & $1575 \mathrm{a}$ & $84.8 \mathrm{~b}$ & $15.5 \mathrm{a}$ & $123 \mathrm{a}$ & $85.2 \mathrm{a}$ \\
\hline \multicolumn{8}{|c|}{ Wine after fermentation } \\
\hline Control & $1563 \mathrm{ab}$ & $12.3 \mathrm{~cd}$ & $1465 \mathrm{a}$ & $81.7 \mathrm{bc}$ & $3.1 \mathrm{c}$ & $43.8 \mathrm{c}$ & $23.8 \mathrm{~d}$ \\
\hline FR & 1869 a & $65.9 \mathrm{~b}$ & $1564 \mathrm{a}$ & $233 \mathrm{a}$ & $6.6 \mathrm{~b}$ & $70.9 \mathrm{~b}$ & $48.4 \mathrm{~b}$ \\
\hline \multicolumn{8}{|c|}{ Wine after maturation } \\
\hline Control & $1666 \mathrm{ab}$ & $4.8 \mathrm{~d}$ & 1617 a & $41.7 \mathrm{~d}$ & $2.2 \mathrm{c}$ & $22.1 \mathrm{~d}$ & $24.8 \mathrm{~d}$ \\
\hline FR & $1456 \mathrm{~b}$ & $7.2 \mathrm{~d}$ & $1382 \mathrm{a}$ & $62.7 \mathrm{~cd}$ & $3.9 \mathrm{c}$ & $50.0 \mathrm{c}$ & $41.1 \mathrm{bc}$ \\
\hline
\end{tabular}

$F R$ flash release

Values within columns followed by different letters differ significantly from each other at $P<0.05$

\section{Anthocyanins}

Anthocyanins contribute to red color of wine. In the wine investigated in this study, five anthocyanin glycosides were identified, including delphinidin, cyanidin, petunidin, peonidin and malvidin of -3-O-glucoside (Table 2), which corresponded to other works [10, 23-25]. Malvidin-3-O-glucoside is considered to be the most abundant anthocyanin in Pinot noir that represents more than $60-90 \%$ of the total anthocyanin content [20,27].

FR must from Pinot noir contained significantly more anthocyanins $(202 \mathrm{mg} / \mathrm{L})$ than the must obtained by traditional method (25.8 mg/L). High temperature of FR maceration did not significantly affect the amount of anthocyanins, as the operation time was short and the grapes were quickly cooled. In addition, vacuum positively affected polyphenol content as it stopped decomposition of these compounds caused by oxidation. Paranjpe et al. [12] reported anthocyanin content in juice extracted by flash vacuum expansion to be significantly higher $(316 \mathrm{mg} / \mathrm{L})$ than that obtained by other methods, like enzyme processing $(253 \mathrm{mg} / \mathrm{L})$, cold pressing $(191 \mathrm{mg} / \mathrm{L})$ or heat treatment $(205 \mathrm{mg} / \mathrm{L})$. Higher concentration of anthocyanins in the flash vacuum expansion-treated juice indicates that the process would yield darker-colored juices than enzyme processing, and thus, it may be more desirable for the industry. However, the changes during wine-making process observed in our study significantly reduced these amounts- to $7.2 \mathrm{mg} / \mathrm{L}$ for FR wine and $4.8 \mathrm{mg} / \mathrm{L}$ for control Pinot noir wine. Nevertheless, during the fermentation and aging, many factors, such as wine $\mathrm{pH}$, alcohol, $\mathrm{SO}_{2}$, temperature, light or metal ions, were found to affect the concentration of anthocyanins. Besides, anthocyanins can also 'interact' with other phenolics, including phenolic acids, flavonols and flavan-3-ols to form co-pigments that largely improve color stability of red wines [23]. Despite greater amount of anthocyanins at every stage of production in Pinot noir wine produced by means of FR as compared to control, a decrease in these compounds was also more rapid in this variant. Reduction in anthocyanins in wine after fermentation and after maturation, compared to the must, was 52.4 and $81.5 \%$ in control, and 67.5 and $96.4 \%$ in FR sample. These results show the need for additional methods for protecting sensitive bioactive compounds from disintegration, e.g., reducing the aeration of wine during treatments.

Each grape species and variety has a unique set of anthocyanins. They are accumulated mainly in the berry skin, but in some other cultivars, anthocyanin pigments may accumulate in the flesh [26]. Pinot noir grapes are typically low in anthocyanins and additionally nonacylated, which might reduce their stability and make them a challenging raw product for wine manufacture [13, 21]. Acylated anthocyanins are important because they participate in intramolecular co-pigmentation processes by protecting the flavylium cation. Urcan et al. [20] who analyzed anthocyanin profile of Feteasca neagra grape berries found better color stability in this cultivar as compared to that of Pinot noir berries. This was due to the fact that Feteasca neagra cv. is devoid of acylated anthocyanins.

Carew et al. [22] recommended microwave maceration as a solution for winemakers working with expensive Pinot noir grapes. Wine obtained using microwave maceration was richer in total phenolics, anthocyanins and tannins and showed higher color density than control wines. Anthocyanin content was much higher in the must after microwave maceration $(250 \mathrm{mg} / \mathrm{L})$ as compared to control $(19 \mathrm{mg} / \mathrm{L})$ and more stable after 6 and 18 months of storage [22]. Bai et al. [23] reported that thermal FR before fermentation may not only improve tannin-to-anthocyanin ratio and increase conversion of anthocyanins to tanninanthocyanin polymers showing the same color properties as anthocyanins, but also enhance wine stability during aging. 
Nonacylated anthocyanins in Pinot noir wine decreased over 2 years from 182 to $33.4 \mathrm{mg} / \mathrm{L}$. Wirth et al. [18] compared traditional maceration and FR in red wines and reported significantly higher content of anthocyanins in the traditional wines ( 250 and $220 \mathrm{mg} / \mathrm{L}$, respectively). This suggests a higher conversion rate of anthocyanins to other molecules during FR process, possibly due to increased extraction of tannins or to heat exposure. Anthocyanin extraction reaches its maximum early on during fermentation and then it decreases. This decrease is due to either reabsorption on the grape skins or yeast cell walls, or is a result of polymerization and formation of polymeric pigments. Increasing the fermentation temperature in the range $15-30{ }^{\circ} \mathrm{C}$ may improve anthocyanin content [10].

\section{Flavan-3-ols}

Flavan-3-ols are present in the grapes mainly as (+)-catechin, (-)-epicatechin and proanthocyanidins. Eight compounds from this group were identified in the must and wine in our research (Table 2). In this study, Pinot noir must obtained by FR was characterized by $12 \%$ higher content of flavan-3-ols $(1575 \mathrm{mg} / \mathrm{L})$ than the control sample $(1406 \mathrm{mg} / \mathrm{L})$. This indicated that this approach provided better extraction results than the traditional wine production method. The amount of flavan-3-ols during wine fermentation was similar as in the must. Following wine maturation, the content of flavanols ranged from $1382 \mathrm{mg} / \mathrm{L}$ for FR wine to $1617 \mathrm{mg} / \mathrm{L}$ for the wine prepared by the traditional method. Changes in the content of flavanols may be due to decomposition or formation of polymeric procyanidins.

Van Leeuw et al. [28] reported that the sum of flavan3 -ols in the wines made of grape cultivars Syrah and Cabernet sauvignon was lower than that in the wines made of Merlot and Pinot noir cultivars. Pinot noir wines showed the highest content of flavan-3-ols that amounted to $326 \mathrm{mg} / \mathrm{L}$, whereas the results from this study were much higher. This may be due to better extraction of these compounds from skin and seeds of berries, by using FR method of maceration.

Flavan-3-ols accumulate in the seeds and in the skin of grape berries and represent $13-30 \%$ of total phenolic content in red grapes, which makes them second most abundant flavonoids in grapes. Flavan-3-ols and procyanidins are very important compounds in wine. They are responsible for color stabilization, oxidative browning and aroma loss. Flavan-3-ols have a direct impact on the complexity of wine taste and mouthfeel, being responsible for bitterness of wine and also associated with astringency [25].

\section{Phenolic acids}

Several cinnamic acids are present in grapes and wine. In grapes, they usually occur as esters, particularly of tartaric acid. The main hydroxycinnamic acids found in the grapes are tartaric esters of caffeic, $p$-coumaric and ferulic acids, yielding -cis and -trans forms of caftaric, coutaric and fertaric acids, respectively [10]. Phenolic acids play a critical role in the development of bitterness and astringency properties of wine. Compared with the amount of hydroxycinnamic acids, hydroxybenzoic derivatives are commonly low in wine. Caftaric and coutaric acids were the main hydroxycinnamic acids in Pinot noir grapes [25], similarly as in our study. The content of phenolic acids in the investigated wines ranged from 41.7 to $62.7 \mathrm{mg} / \mathrm{L}$ for control wine and FR, respectively. In the must ( $57.0 \mathrm{mg} / \mathrm{L}$ for control and $84.8 \mathrm{mg} / \mathrm{L}$ for FR), the content of phenolic acids in wine after fermentation decreased in control sample and increased significantly in the case of FR wine. After maturation, the content of phenolic acids in this study decreased by 26.0 and $26.9 \%$ (for FR and control, respectively). However, the concentration of tartaric esters of hydroxycinnamic acids (sum of caftaric and coutaric acids) was much higher in FR wine than in the wines prepared in the traditional way. Bai et al. [23] reported increasing content of phenolic acids along with wine aging and explained it by a decrease in their corresponding esters and a hydrolysis of the acylated anthocyanins.

\section{Flavonols}

Flavonols are present only in glycosylated form in grape skins and are hydrolyzed during fermentation that results in increased presence of aglycones in wine. The main flavonols identified include quercetin, isorhamnetin, kaempferol and myricetin, and their glycosides [10, 26]. This group of compounds was present in the smallest amount, both in Pinot noir must and wine, and was represented by four derivatives, i.e., two quercetin-3-O-glucosides and -3-O-glucuronide, and isorhanmetin-3-O-glucoside. FR maceration did not affect $(p<0.05)$ the initial content of flavonols (15.5 and $15.9 \mathrm{mg} / \mathrm{L}$ for FR and traditional method, respectively). The content of flavonols in the final product after storage period was about five times lower, with a slight advantage of FR wine ( 3.9 vs. $2.2 \mathrm{mg} / \mathrm{L})$. Flavonols are yellow pigments that are masked by anthocyanins in red wines. However, flavonols are also important cofactors of color enhancement, affecting red wine color by means of copigmentation [25].

\section{Antioxidant activity}

Although most phenolics show antioxidant properties, studies have proved that anthocyanins followed by flavonols, phenolic acids and resveratrol contribute the most to the antioxidant potential of grape juice and wine [10, 
26]. Considering the fact that antioxidants may act synergistically rather than individually, it is good to show antioxidant capacity by using more than one assay. In this study, ABTS and FRAP methods were used. These assays measure the ability of natural antioxidants to scavenge free radicals using different chemical reaction mechanisms $[11,27]$. FR maceration positively affected preservation of phenolic compounds responsible for antioxidant activity. Both ABTS and FRAP assays showed two times higher initial antioxidant activity for the must macerated by using FR (123 and $85.2 \mathrm{mmol}$ Trolox/mL), as compared to the traditional method (56.5 and $37.9 \mathrm{mmol}$ Trolox $/ \mathrm{mL}$ ). It is probably mostly related to much higher anthocyanin content (almost 10 times higher in the must obtained by FR vs. control), than the presence of other groups of polyphenols. However, fermentation and maturation decreased the content of phenolics and hence also antioxidant activity of the tested wines. Antioxidant activity (measured by ABTS assay) decreased in the control wine from $22.5 \%$ after fermentation to $60.8 \%$ after maturation. In FR wine, two times greater reduction was measured after fermentation (42.4\%), but in the final product after maturation, the loss of antioxidant activity was slightly lower (59.4\%) and comparable to the control. Even though the reduction in antioxidant activity of both tested variants was similar, still the wine produced by FR method was characterized by almost twice as high antioxidant activity as the control wine (ABTS and FRAP assays). In the tested Pinot noir wines, a strong correlation was determined between anthocyanins content and antioxidant activity $\left(r^{2}=0.84\right.$ and 0.79 for ABTS and FRAP assay, respectively), and a significant correlation was found between flavan-3-ols, and total polyphenols $\left(r^{2}>0.35\right)$.

Most polyphenols were demonstrated to be capable of positively correlating to their in vitro total antioxidant activity [27]. Wirth et al. [18] reported that anthocyanins are the strongest antioxidants and may partially protect the other classes of polyphenols from oxidation.

Du Toit and Oberholster [10] concluded that vinification practices only slightly affected phenolic content and antioxidant potential, while the changes in phenolic composition of wine during storage and aging had a greater effect on its antioxidant potential. Giovinazzo and Grieco [26] showed the effects of thermo-vinification on the antioxidant potential, total phenolics and resveratrol content in Merlot, Cabernet sauvignon, Pinot noir and Prokupac wines. They confirmed that wine samples produced by thermo-vinification had higher amount of phenolic compounds and exhibited higher antioxidant activity.

Wine aging also changed its phenolics profile, as these molecules may undergo oxidation, condensation and polymerization reactions [26].

\section{Color assessment}

The appearance of food or beverages affects an initial judgment made about a product including its safety, sensory characteristics and acceptability.

FR maceration limited aeration of the must and reduced unwanted changes. Color of the investigated wines was assessed using CIE $L^{*} a^{*} b^{*}$ model. In the must, $L^{*}$ (27.32 and 27.34) and $a^{*}$ (4.06 and 4.32) parameters were almost identical for both variants, and only $b^{*}$ parameter was higher in the must where FR was used (0.54) than in control (0.28). During fermentation, $L^{*}$ and $a^{*}$ increased in both samples of Pinot noir wine and this was responsible for more light and red color. Lighter color was observed in the control wine. During maturation, an increase in $b^{*}$ was noticed that corresponded to more yellow color, while $L^{*}$ decreased to a similar level that was measured in the must. Wirth et al. [18] reported that FR and traditional wines contained different types of pigments. FR wines also appeared lighter $\left(L^{*}\right)$, less red $\left(a^{*}\right)$ and more yellow $\left(b^{*}\right)$ than the traditional ones.

Different changes in chemical composition taking place during wine production affect its color. Anthocyanins from grape skins and polymeric pigments contribute to the beverage color. Once the grapes are crushed, polymeric pigments begin to form and their concentrations continue to increase with time [10]. Anthocyanins and flavan-3-ols are highly reactive and form various derivative pigments and tannins during wine-making and aging, potentially altering wine color. A replacement of the original grape anthocyanins with more stable pigments changes the initial purplered color of red wines to the orange red hue of older wines.

Cross-linking reactions between anthocyanins and flavan-3-ols yield new polymeric pigments. The latter reactions produce purple pigments, in which flavan-3-ol and anthocyanin units are linked through methylmethine bridges, commonly called ethyl bonds. In wine, acetaldehyde is a product of yeast metabolism and ethanol oxidation, whereas pyruvic acid is produced by lactic bacteria and may also result from an oxidation of malic and lactic acids by hydroxyl radicals generated in Fenton reaction. Although both compounds are the products of microbial metabolism, their concentration and concentration of their derivatives (ethyl-bridged oligomers, pyranoanthocyanins) in wine can be much increased as a result of oxygen exposure, which is a key factor in wine-making and bottle-aging. Indeed, during the wine-making process, some operations like pressing, cooling, pumping-over and bottling may introduce oxygen in an uncontrolled way [10, 18]. It is important to note that highly colored grapes and total anthocyanin content do not necessarily produce highly colored wines; any differences are probably related to the 
easiness of anthocyanin extraction from grape skins into grape must [7].

\section{Conclusion}

Apart from others factors like grape cultivar or harvesting, wine-making process affects wine quality to a large extent. To obtain a product with high polyphenol content and antioxidant activity, the flash release method may be used. Due to vacuum conditions during maceration, sensitive compounds such as anthocyanins are better extracted and preserved. Despite lower content of total polyphenols in wine after maturation (1435 vs. $1687 \mathrm{mg} / \mathrm{L}$ in control), the antioxidant activity of FR wine was more than two times higher. High correlation between antioxidant activity (by ABTS and FRAP) and the content of anthocyanins was determined in both types of examined wines. Considering the results, FR maceration may be recommended as a method for improving the amount of bioactive compounds and antioxidant activity of wine. This kind of treatment is especially useful for grape cultivars that contain little anthocyanins, like Pinot noir. The must produced by FR had almost 10 times higher content of anthocyanins, as compared to the traditional method. The knowledge about qualitative and quantitative profile of polyphenols in Pinot noir wine is very important to predict wine aging attitude, and it can help to solve problems related to color stability, especially during long aging period. Therefore, the combination of flash release maceration and fermentation on pomace provides a perspective of further research on obtaining wines with high polyphenol content, stable during the entire period of production and storage influence of different maceration process on sensory attributes, and customer's preference may also be considered for future studies.

Acknowledgements This work was financially supported by the National Science Centre (NCN) UMO2013/09/B/NZ9/01745. Publication was supported by Wroclaw Centre of Biotechnology programme, the Leading National Research Centre (KNOW) for years 2014-2018. The authors would like to thank Mateusz Michalak, for assistance in the preparation of wine.

\section{Compliance with ethical standards}

Conflict of interest The authors declare no competing financial interest.

Compliance with ethics requirements All authors declare that this article does not contain any studies with human or animal subjects.

Open Access This article is distributed under the terms of the Creative Commons Attribution 4.0 International License (http://creativecommons.org/licenses/by/4.0/), which permits unrestricted use, distribution, and reproduction in any medium, provided you give appropriate credit to the original author(s) and the source, provide a link to the Creative Commons license, and indicate if changes were made.

\section{References}

1. Kaczmarska E, Gawronski J, Dyduch-Sieminska M, Najda A, Marecki W, Zebrowska J (2015) Turk J Agric For 39:394-402

2. Mishra PK, Ram RB, Kumar N (2015) Turk J Agric For 39:451-458

3. Ipek A, Yilmaz K, Sikici P, Tangu NA, Oz AT, Bayraktar M, Ipek M, Gulen H (2016) Biochem Genet 54:313-325

4. Tsou C, Li L, Vijayan K (2016) Biochem Genet 54:270-282

5. FAO (2014) FAOSTAT. http://faostat.fao.org

6. The International Wine and Spirit Research (2011) http://www. theiwsr.com

7. Costa E, da Silva JF, Cosme F, Jordao AM (2015) Food Res Int 78:302-312

8. Valentin D, Parr WV, Peyron D, Grose C, Ballester J (2016) Food Qual Prefer 48:251-261

9. Bindon KA, Carew AL, Mierczynska-Vasilev A, Kassara S, Kerslake F, Smith PA (2016) Food Chem 199:838-846

10. du Toit W, Oberholster A (2014) In: Preedy V (ed) Processing and impact on antioxidants in beverages, 1st edn. Elsevier, London

11. Liu X, Li J, Tian Y, Liao M, Zhang Z (2016) PLoS ONE. doi:10.1371/journal.pone.0151276

12. Paranjpe SS, Ferruzzi M, Morgan MT (2012) LWT Food Sci Technol 48:147-155

13. Carew AL, Close DC, Dambergs RG (2015) J Appl Microbiol 118:1385-1394

14. Morel-Salmi C, Souquet JM, Bes M, Cheynier V (2006) J Agric Food Chem 54:4270-4276

15. Wojdyło A, Nuncio Jauregui PN, Carbonell-Barrachina AA, Oszmiański J, Golis T (2013) J Agric Food Chem 61:12072-12084

16. Re R, Pellegrini N, Proteggente A, Pannala A, Yang M, RiceEvans C (1999) Free Radic Biol Med 26:1231-1237

17. Benzie IFF, Strain JJ (1996) Anal Biochem 239:70-76

18. Wirth J, Morel-Salmi C, Souqueta JM, Dieval JB, Aagaard O, Vidal S, Fulcrand H, Cheyniera V (2010) Food Chem 123:107-116

19. Song J, Smart R, Wang H, Dambergs B, Sparrow A, Qian MC (2015) Food Chem 173:424-431

20. Urcan DE, Lung ML, Giacosa S, Torchio F, Ferrandino A, Vincenzi S, Segade SR, Pop N, Rolle L (2016) Int J Food Prop 19:76-98

21. Carew AL, Gill W, Close DC, Dambergs RG (2014) Am J Enol Viti 65:401-406

22. Carew AL, Sparrow AM, Curtin CD, Close DC, Dambergs RG (2014) Food Bioprocess Technol 7:954-963

23. Bai B, He F, Yang L, Chen F, Reeves MJ (2013) Food Chem 141:3984-3992

24. Feng H, Yuan F, Skinkis PA, Qian M (2015) Food Chem 173:414-423

25. Ferreira V, Fernandes F, Pinto-Carnide O, Valentao P, Falco V, Martín JP, Ortiz JM, Arroyo-García R, Andrade PB, Castro I (2016) Food Chem 194:117-127

26. Giovinazzo G, Grieco F (2015) Plant Foods Hum Nutr 70:454-462

27. Leong SY, Burritt DJ, Oey I (2016) Food Chem 196:833-841

28. Van Leeuw R, Kevers C, Pincemail J, Defraigne JO, Dommes J (2014) J Food Comp Analysis 36:40-50 